\title{
VOLVER A SEPÚLVEDA LEYTON: PARA UNA NUEVA NOVELA SOCIAL
}

\author{
Returning to Sepúlveda Leyton: For a new Social Novel
}

Daniel Noemi Voionmaa*

\section{Resumen}

Este ensayo busca revisitar y repensar la producción del escritor chileno Carlos Sepúlveda Leyton (1895-1941), en particular sus novelas Hijuna y Camarada y, de este modo, contribuir a y continuar la labor crítica de recuperación de su producción, en particular, y de la novela social, en general. Se argumenta que Sepúlveda Leyton propone una novela social radicalizada y que su lugar en la historia de la literatura chilena no es el de una "transición" como han argumentado la mayoría de los críticos. Finalmente, desde el análisis de aquellos textos, se pretende discutir y reconsiderar la división tradicional que se establece entre textos realistas y textos de vanguardia.

Palabras clave: Literatura chilena, Carlos Sepúlveda Leyton, Novela Social, Realismo, Vanguardia.

\section{Abstract}

This essay aims to revisit the production of a rather neglected Chilean writer, Carlos Sepúlveda Leyton (1895-1941). Through the analyses of his novels Hijuna and Comrade, it argues that Sepúlveda Leyton is not just a transitional figure in Chile's social novel tradition; on the contrary, his work constitutes a radicalization of the social novel and as such it should deserved a more notorious position in Chile's literary historiography. Finally, from the study of his work it emerges the need for a reconsideration of the traditional divisions between realism and avant-garde.

Key words: Chilean Literature, Carlos Sepúlveda Leyton, Social Novel, Realism, Avant-Garde.

Las pretensiones de este estudio son revisitar y repensar la producción del escritor chileno Carlos Sepúlveda Leyton (1895-1941), ${ }^{1}$ en particular sus novelas Hijuna y Camarada, y de este modo contribuir a y continuar la labor crítica, de recuperación y de rescate, iniciada por Jaime Valdivieso y Nelson Osorio, entre otros. $^{2}$ A partir del análisis de aquellos textos, se pretende discutir y reconsiderar la

\footnotetext{
${ }^{1}$ Es de notar que todo intento por clasificar a Sepúlveda Leyton en alguna de las "generaciones" establecidas resulta, al menos, problemático. Por nacimiento se acerca a los de la generación del 20; por fecha de publicación, a los del 38; por temática, a estos últimos también. Más allá de ese intento, a fin de cuentas improductivo, es importante notar las conexiones estéticas e ideológicas del autor con escritores que suelen ser vinculados al realismo social (entre otros, Alberto Romero, 1896-1981; Nicomedes Guzmán, 1914-1964; Eugenio González Rojas, 1903-1976). Repensar la producción de Sepúlveda Leyton implica, así, el trabajo más amplio de revisitar la producción "realista social" de esos años.

${ }^{2}$ Es Jaime Valdivieso quien tiene el estudio más detallado hasta el presente sobre la producción de Sepúlveda Leyton. Su Un asalto a la tradición. Sepúlveda Leyton: Vida y obra (1963) incluye
} 
división tradicional que se establece, en particular referido a la producción literaria de primera mitad del siglo XX, entre realismo(s) y vanguardia(s). ${ }^{3}$

\section{1.- CONTEXTO CRÍTICO.}

Sepúlveda Leyton ha sido usualmente relacionado con la novela social y es considerado "uno de los primeros autores en tratar de expresar la vida del moderno proletariado urbano" (Vitale, 2001:124). ${ }^{4}$ Tanto por el sujeto protagonista de su producción novelística como por las características de su prosa, su escritura suele calificarse como "realista" o, al menos, como un intento realista. Osorio señala al respecto que en su obra "prima sobre todo la voluntad de hacer de la forma un instrumento al servicio de la expresión de una realidad, prima el intento de superar la subjetividad en beneficio de la plasmación poética de un mundo social hasta entonces escamoteado o falsificado" (1967:56). Si bien, para Osorio, Sepúlveda Leyton no fue del todo exitoso, su escritura abrió una brecha y una nueva época para la novela social chilena. De hecho, su producción se ubica en la tradición de aquellas novelas publicadas con anterioridad y que, en palabras de Walter Fuentes, "se orientan hacia un realismo valorado por la historia literaria en virtud de su 'objetividad documental' y sensibilidad ético-denunciativa frente al trasfondo social del período" (1990:11), a la vez que, como se mostrará, representa un quiebre profundo con dicha tradición; esto es, comparte "una postura reivindicadora del mundo popular y [...] una representación crítica del espacio oligárquico" (11), pero difiere drásticamente en el modo de la representación y de la ideología "reformista" que Fuentes le atribuye a las

una detallada y emotiva biografía, junto con un cuidadoso estudio de las características técnicas de la prosa del autor. Nelson Osorio, en tanto, en su artículo de 1967 "Sepúlveda Leyton: Tradición y modernidad", inicia su texto señalando que sobre Sepúlveda Leyton "se ha escrito poco". Si bien en el casi medio siglo que nos separa de la publicación de Valdivieso han aparecido notables contribuciones al estudio de la narrativa que nos concierne, estas siguen siendo esporádicas y la producción de Sepúlveda Leyton, así como la gran mayoría de la de aquellos años que cayó (tuvo la desgracia de caer) bajo el calificativo de "realismo social", continúa siendo minusvalorada. Así, en un sentido más amplio, este ensayo pretende también contribuir mínimamente a lo que John Beverley, a fines de la década de los ochenta, llamara "una reivindicación de esa literatura narrativa producida en América Latina, principalmente en los años 30 y 40, y generalmente en relación con los proyectos políticos de las izquierdas" (167), labor que continuaba, a su vez, la emprendida por Françoise Perus.

${ }^{3}$ Este ensayo parte, también, de la convicción respecto a que, en tiempos de crisis —como los presentes - resulta revelador volver la mirada a una escritura que muestra la crisis de su momento en y desde la literatura misma; una literatura donde la crisis individual y permanente lucha de su autor va de la mano con la incertidumbre y efervescencia social que se vivía en aquellos años.

${ }^{4}$ Tanto Vitale como Osorio citan el comentario de Ricardo Latcham (1963), donde éste señala que "la corriente social que imperó en la novela y el cuento chilenos entre 1940 y 1950" (Osorio, 1967:56; Vitale, 2001:124) se anticipa en la producción de Sepúlveda Leyton.

${ }^{5}$ En su estudio sobre la novela social chilena durante el primer cuarto del siglo XX que cumplen esta caracterización, Fuentes analiza Casa Grande de Orrego Luco, El crisol y Robles, Blume y Cía, de Fernando Santiván y El Roto, de Joaquín Edwards Bello. 
primeras. ${ }^{6}$ De modo inverso, las novelas de Sepúlveda Leyton, pensando desde esa "tradición" realista, son antecedentes significativos de la obra de José Donoso, por ejemplo, en la cual el realismo llegaría a su plenitud y superación. Este lugar "intermedio", que se expresa también en la técnica empleada por Sepúlveda Leyton ha demostrado ser sumamente problemático para la crítica.

En efecto, para Osorio, Sepúlveda se ubica en un lugar de transición, de clara incomodidad crítica, donde "se conjugan viejas técnicas folletinescas y tradicionales con búsquedas renovadoras no siempre bien logradas" (56-7). Esta dificultad crítica que proviene de lo que puede calificarse un encabalgamiento de técnicas, también se advierte en el cuidadoso análisis de Valdivieso quien resume el "universo novelístico" de Sepúlveda "como una búsqueda angustiosa de la verdad, de la autenticidad y, a la vez, una crítica constante, a través de un "realismo caricaturesco", de todo lo falso y desnaturalizado de las instituciones burguesas" (1963:113). ${ }^{7} \mathrm{Y}$ es, principalmente, a través del uso de la elipse, innovación técnica que lo conecta con la "modernidad literaria" a la vez que anticipa la escritura del Boom, que esto se lleva a cabo. Así, añade Valdivieso, "su técnica corresponde a una 'metafísica"” (82).

Los acercamientos de Osorio y de Valdivieso destacan el carácter de precursor, incluso de visionario, que tendría la producción de Sepúlveda Leyton; ${ }^{8}$ en la medida que sus novelas dan paso, y posibilitan, un giro en la novela social chilena posterior. Efectivamente, ello puede ser articulado de ese modo. Sin embargo, ese enfoque está dando cuenta de la necesidad de mantener ciertos conceptos y nociones críticoliterarias; una necesidad que resulta si no contradictoria al menos problemática para lograr una más cabal apreciación de la producción de Sepúlveda Leyton. Tómese como ejemplo el concepto de "realismo caricaturesco". La descripción que se hace de éste - eliminación de ciertos aspectos, uso de elipsis, carácter irónico- parece acercarse más a cierto arte que suele ser calificado de vanguardia ¿Por qué su empleo de "recursos modernos" no basta para calificarlo de "vanguardista" en lugar de "realista"? ¿Qué es lo que lo convierte en lo uno o en lo otro? No se trata, por cierto, de

6 Para Fuentes, las novelas que analiza buscan quitarle al "movimiento obrero su carácter revolucionario", (1990:16), este "reformismo" se advierte en la "tipificación de un personaje popular limitado a la primariedad de los instintos" (16) y en la figura "idealizada del héroe", quien "se levanta como centro ideal" entre "la retrogradación de la vieja oligarquía y el discurso "anárquico" de las clases populares" (17).

${ }^{7}$ El "realismo caricaturesco" es definido como uno "en el que las cosas, los hechos, las situaciones, los personajes, se describen sólo a través de ciertos rasgos, de ciertas características. La caricatura se forma por eliminación. Toma solamente los aspectos más relevantes dejando fuera los superfluos" (Valdivieso, 1963:82).

${ }^{8}$ Valdivieso recalca que, probablemente, la gran mayoría del uso de técnicas "modernas" por parte de Sepúlveda Leyton no provino de una imitación de modelos foráneos (Joyce, Woolf, Faulkner, etc.), sino que surgió de su propia necesidad expresiva y genio.

${ }^{9}$ Valdivieso analiza prolijamente el uso de diversas "perspectivas en la narración", el "uso del paréntesis", la elipsis, "procedimientos repetitivos" que otorgan ritmo a la novela; diversos modos de "corriente del pensamiento", recursos cinematográficos, etc. 


\section{Daniel Noemi}

proponer una inversión en la categorización del escritor ("Sepúlveda Leyton es un escritor vanguardista"), sino de iniciar la crítica desde la constatación de lo insuficiente e inadecuado de dicha división. Asimismo, como hemos referido, la noción de "precursor" es significativa, pero no puede emplearse para restarle valor a una producción ("precursor" encierra la connotación de "no tan bueno como" lo posterior o, al menos, un grado de inmadurez o falta de desarrollo). La novelística de Sepúlveda Leyton es mucho más que "precursora" o facilitadora de nuevos caminos para la novela social chilena; es en sí un camino y, a pesar de su brevedad, literal y literariamente, completa. $^{10}$ Finalmente, debe insistirse en la estrecha relación entre la vida de Sepúlveda Leyton y su obra, no para caer en una crítica biográfica, sino para profundizar en el sentido político de toda producción artística, aspecto clave en este caso.

\section{2.- RELACIÓN ENTRE VIDA Y OBRA}

En sus 46 años de vida, Carlos Sepúlveda Leyton publicó solamente tres novelas $^{11}$ que bien pueden leerse como una trilogía que corresponde a tres momentos de la vida de Juan de Dios, el alter ego del autor. Hijuna (1934) refiere la infancia; La Fábrica (1935), los años de juventud y su vida como estudiante en la Escuela Normal (la mayor parte de la novela trata del primer día), y Camarada (1938) que relata su vida adulta como profesor. Ramiro Rivas señala que esta correspondencia es bastante más profunda que una simple narración autobiográfica. Para él, son muy pocos los escritores chilenos que pueden demostrar "tal unidad entre literatura y vida. Ambas conforman un todo concreto, verosímil, basado en principios morales y éticos, sociales y políticos, que no se contraponen en su labor creativa" (1995:3). En efecto, la labor de Sepúlveda Leyton como educador y luchador por los derechos de los profesores, es clave para analizar estas novelas. Ellas son parte de su enseñanza y de su gran preocupación social; pero, al mismo tiempo, muestran un cuidado por el lenguaje -que algunos han llamado discutiblemente "romántico" o lleno de "arranques líricos"- que produce una amalgama única. La esperanza final - la posibilidad socialista - se da, antes que nada, en y a través del lenguaje, metáfora de la educación misma de toda la sociedad.

Esta "unidad" remite a la idea desarrollada por Ridenti (2000) respecto a aquellos políticos que hicieron de su vida "una obra de arte". Aquí es posible pensar

\footnotetext{
${ }^{10}$ Como "novela social", las de Sepúlveda Leyton dan cuenta de lo que Gil Casado denomina un "estado de cosas" (1967:230), esto es, presenta testimonio de una determinada realidad de una clase social que puede ser presente o pretérita. Este "estado de cosas", que se manifiesta tanto en el contenido como en la técnica empleada, puede pensarse como "precursor" de uno por venir, pero, más significativamente, tiene validez y relevancia en sí.

${ }^{11} \mathrm{Su}$ obra incluye, además, una serie de crónicas y críticas literarias publicadas en diversos diarios y revistas. Existiría, además, una cuarta novela, pero el manuscrito — según Jaime Valdivieso - se ha perdido o destruido.
} 
dicha relación de modo inverso y complementario: la obra de arte, la producción literaria es parte inseparable de la labor política y social emprendida, ella busca apoyar su visión de lo social y su participación en la actividad gremial y política. ${ }^{12}$

\section{3.- EL INICIO: HIJUNA}

Las tres novelas conforman una sola serie en el desarrollo vital del protagonista, para lo cual se emplean variadas perspectivas. Es su peculiar y variado posicionamiento, el "punto de vista" como recalca Nelson Osorio, lo que contribuirá a la creación de una estructura de sentimiento característica de su producción la que, a la vez, da cuenta de su visión política y de la realidad social. Para Sepúlveda Leyton, la educación constituye el elemento central para el desarrollo de la sociedad. ${ }^{13}$ Consecuentemente, el desarrollo y evolución de Juan de Dios en Hijuna, la novela que más atención crítica ha recibido, adquiere los rasgos de un Bildungsroman. En ella, calificada por Nicomedes Guzmán como "auténtica novela del pueblo chileno" (1941:357), el protagonista se transforma de niño en joven: "Huye y se diluye la infancia, y la juventud estalla como una flor de granado, abierta y entregada a todos los vientos..." (1995:112). Los diferentes cuadros y escenas entregan una visión de la realidad social en que vive Juan de Dios y de los cambios en su vida, de su aprendizaje, que están claramente determinados por las diferentes etapas de su enseñanza. La primera es el aprendizaje en la calle; luego, gracias a la apertura de una escuela en su barrio, la enseñanza formal en la que destaca Arriaza, uno de los maestros, quien se convierte en un modelo para él, figura clásica de la novela de formación. Tanto así, que de los tres amigos — Juan de Dios, Perucho y Enrique- que tienen éxito en los estudios y que de la Escuela han logrado ser aceptados en el Liceo, será sólo el protagonista y narrador, después de dos años, quien decida seguir la misma carrera que Arriaza y asistir a la Escuela Normal. ${ }^{14} \mathrm{Al}$ final, Juan de Dios debe despedirse de sus amigos, de su perro Nato, quien ha sido su más fiel compañero a lo largo de todo el relato y de Lucía, su (primer) amor. A fin de cuentas, Juan de Dios ha logrado salir de su circuito, donde todos parecen condenados a una existencia miserable. Su crecimiento y aprendizaje está, además, influido por la experiencia de la violencia del gobierno durante una huelga que refleja lo que sucede en el país: "Nadie lo sabía, pero en el Norte están matando a los pampinos por carretadas" (91). Durante la huelga, la policía asesina a

\footnotetext{
${ }^{12}$ De hecho, el inicio de su creación literaria se produce en momentos en que ha sido exonerado de su trabajo de maestro.

${ }^{13}$ La suya es una lucha en medio de una realidad marcada por la división de clases y por las controversias ideológicas en muchas ocasiones contradictorias. Esta lucha y enfrentamiento con la realidad se expresa en la novela a través del crecimiento del personaje principal.

${ }^{14}$ Interesa notar que Enrique, quien también quiere convertirse en profesor, "se ve obligado a apartarse de nosotros para seguir los estudios de la Escuela de Agricultura..." (103) y Perucho, quien sueña con ser comerciante, debe entrar, obligado por su padre, en la Escuela de Artes y Oficios. Son éstas las alternativas de desarrollo para aquellos que pertenecen al círculo de pobreza que impone la estructura social.
} 


\section{Daniel Noemi}

varios de los personajes que hemos conocido y que viven en el barrio. La respuesta popular, que se articula desde la derrota, ha sido también violenta: "Ayer la gente le dio el 'bajo' a dos oficiales" (99). Cuando todo ha terminado, el narrador da cuenta de la división que permanece y se perpetúa en el país. Su visión ya muestra la ironía que se acrecentará en las dos novelas posteriores. Mientras los "diarios obreros traen unos monos que representan "el triunfo de la causa..." [...] La prensa seria proclama en títulos muy grandes que la Patria se ha salvado y que los chilenos, los buenos chilenos caídos en su defensa, vivirán imperecederamente en el recuerdo inmarcesible de las generaciones..." (100). El lenguaje, gran preocupación en las tres novelas, vacila en ésta entre la capacidad linguística de un niño y la descripción de la realidad exterior que se hace a través de las palabras de otros. La inocencia que presupone la mirada infantil permite descubrir una realidad más profunda: el desvelamiento de la verdad que se expresa directa y sin disfraces. Así, luego de referir que los diarios pequeños "endilgan vibrantes argumentos y hacen un análisis "dialéctico" de la huelga y constatan, constatan, constatan...", surge la pregunta directa y simple del narrador: "¿Para eso murió tanta gente?” (101).

Se advierte, de esta manera, cómo la realidad social exterior participa en y de la vida de Juan de Dios; esa realidad histórica lo afecta y transforma su modo de comprender el mundo. En efecto, hay una crítica a la actitud de los "hombres" durante la huelga que indica y anticipa la perspectiva que tendrá el joven y el adulto Juan de Dios: "Nos creamos una penosa idea de los hombres que se arrebañan: forman una sola boñiga que se puede pisotear a discreción. Los hombres son todos una pandilla de cobardes" (101). Como se ha dicho, esa visión de la realidad se hace más compleja desde la sencillez que otorga la perspectiva "de niño". En el texto están permanentemente en tensión esa visión con la otra realidad, aquella que es todavía "incomprensible" para Juan de Dios, pero que ha de aprender a como dé lugar. La misma fragmentación que se advierte en la novela, dada por la conformación de diversas escenas que parecen no guardar relación entre ellas más allá de una relación en el tiempo y el espacio, es relevante para dicha perspectiva: el mundo es, para Juan de Dios, difícil de aprehender y comprender a través de su lenguaje y está armado por piezas diversas que poco a poco — a través de la educación - irán adquiriendo sentido y se constituirán en una "auténtica narrativa". Sí: la escritura de la novela — desde un tiempo posterior de enunciación- es el aprendizaje mismo del protagonista. El ejercicio de la memoria que intenta ser escrito desde la perspectiva de un niño no puede evitar su posterioridad, su ser externo a ella misma, lo que agrega otro factor más a la tensión en la percepción del mundo.

Ahora bien, el lenguaje y la técnica que emplea Sepúlveda Leyton problematiza la visión del protagonista desde la fragmentación del relato, los silencios y las incomprensiones que disminuyen a medida que se avanza cronológicamente. Se trata, a un mismo tiempo, del aprendizaje individual de Juan de Dios y del aprendizaje de lo 
social y político, elementos que son inseparables y que permiten pensar en un particular carácter revolucionario del texto: la transformación personal va de la mano de la transformación social. Y esto se logra a través de la secuencia de cuadros que parecen combinar técnicas expresionistas con otras cubistas o, como plantea Silva Castro, por medio del ir "mostrando en iluminaciones parciales los hechos de los personajes" (Valdivieso, 1963:39). Los quiebres en la narración, el empleo de la elipsis, alteran la visión de la realidad y contribuyen, así como lo hacía la perspectiva del narrador infantil, al descubrimiento de una realidad más compleja; una realidad "más real" a la cual se llega por medio de la desestructuración de la narración lineal. Así, se observa cómo técnicas características de la vanguardia contribuyen al realismo profundo del texto.

Es cierto que hay un sentimiento de extrañeza en el relato, que surgen vacíos de sentido, contradicciones; que, incluso, hay violentos choques en el modo como Juan de Dios se expresa (y que pueden ser calificados de inverosímiles); pero todo ello, esa sensación de incomodidad está hablando y describiendo, en gran medida, aquella incapacidad de aprehender la realidad de su momento. Las contradicciones y problemas para caracterizar la época son la época misma. Por eso, es ver sólo un lado de la cuestión cuando se afirma que Sepúlveda "ayuda a romper una corteza, a trizar estamentos tradicionales anquilosados y a abrir una brecha por la que irrumpen otros creadores que señalan una nueva época para la novela social chilena”, lo cual hace del autor "ciudadano de dos mundos, y esto, al mismo tiempo que explica muchas de las debilidades de su creación, marca un hito necesario para aclarar el desarrollo de las nuevas tendencias que se manifiestan en la narrativa social chilena posterior" (Osorio, 1967:57). Es decir, es necesario reiterarlo, Sepúlveda no es sólo un puente de un momento estético (y político) a otro, sino que está plenamente caracterizando su momento, con todas sus carencias y fallas. Se trata de asir el momento de crisis en su condición de inestabilidad.

La multiplicidad de perspectivas y la preocupación por el punto de vista, aspectos que destacan acertadamente tanto Osorio como Valdivieso, ${ }^{15}$ corresponde a la manifestación en la escritura de esa crisis que, poco a poco, lo abarca todo. De esta manera, los personajes funcionan como verdaderas cámaras o instrumentos que registran una realidad que no logra ser abarcada en su totalidad: "El 'punto de vista', por todas estas razones, si bien formalmente es individual, está profundamente marcado por lo social" (Osorio, 1967:59). La imposibilidad de cada personaje de dar cuenta de la totalidad es manifestación de la crisis de sentido que cada uno de ellos experimenta y que se está viviendo, también, en la sociedad.

\footnotetext{
${ }^{15}$ Osorio señala que "La importancia, sin embargo, de este autor reside en el abandono del "punto de vista" tradicional de la observación aparentemente objetiva del narrador omnisciente por uno que le permite enriquecer su visión del mundo, en un intento por entregar una realidad más rica, más profunda y hasta, si se quiere, más real [esto se fija por] una manifiesta separación entre autor y narrador, que tiende a la desaparición del primero" (1967:58). Valdivieso, en tanto, enfatiza cómo el uso de perspectivas diversas permite que los personajes no sean definidos, sino que se permite que "ellos hablen y actúen por sí mismos" (74).
} 
Sepúlveda Leyton logra combinar extraordinariamente el empleo de una pluralidad de recursos literario-estilísticos adscribiéndoles un sentido crítico-social. Es en ese sentido que Valdivieso destaca, en Hijuna en particular, que "dentro de una estructura narrativa aparentemente tradicional", el autor "descubre recursos desconocidos de entonces: uso sistemático de ritmos, símbolos y nuevas posibilidades en el uso del paréntesis" (Valdivieso, 1963:52). El carácter o "sentido visual cinematográfico, la morosidad narrativa, la audacia de las figuras literarias: la repetición de los vocablos, el lenguaje en su capacidad expresiva y poética", (52) son otras de las características que Valdivieso añade (si bien enfatizando, nuevamente, el rasgo de precursor); estas, que se acrecientan en La Fábrica, ${ }^{16}$ llegan a su máxima expresión en Camarada, la novela que cierra la trilogía: "Constituía esta obra un nuevo experimento de lenguaje, sintaxis, planos narrativos

${ }^{16}$ Para Valdivieso, La Fábrica y no Hijo de ladrón de Manuel Rojas, publicada quince años después, es la que "rompe el estatus vigente de la narrativa". Conviene aquí referir dos críticas que La Fábrica recibió poco después de ser publicada, pues muestran la visión de la crítica establecida. La primera corresponde a la aparecida en el diario La Nación de Buenos Aires en que se describe la novela del siguiente modo: "Choques despiadados, frases crueles, resistencias y guapezas y un lugar que descorazona por su chatura, por el menguado nivel docente y cultural: tal es el que nos describe el señor Sepúlveda Leyton con frase corta y maciza de plasticidad caprichosa en muchos casos y chocarrera en otros. Quisiéramos anotar asimismo el desaliño de su prosa áspera, muy desigualmente ordenada. Si bien, descúbrense páginas inconfundibles donde la belleza se expresa con la concisión y la sobriedad de la verdadera maestría, y en otras por una mayor fastuosidad idiomática e imaginativa, abundan en los intermedios los arranques líricos, las abstracciones del alma deprimida y aislada, y es en estos tramos precisamente donde más se echan de ver la desigualdad y la inseguridad de la forma que, al parecer, no cuida el autor pero que, cuando lo hace, la valorización de su obra se acrecienta vivamente" (1935:4). Raúl Silva Castro, en tanto, escribiendo para El Mercurio, no es mucho más favorable: "De Hijuna a La Fábrica el autor no ha mejorado en nada sus condiciones técnicas. La primera es pulcra de lenguaje y ordenada de estilo, si se parangona con La Fábrica: en esta, en efecto, el autor no muestra repugnancia alguna por el reventón, la palabra gruesa, las alusiones coprolálicas, y el estilo se llena de expresiones inventadas por el señor Sepúlveda o recogidas en sitios donde se cuida poco el lenguaje [... L La lengua y el estilo de este libro están lamentablemente descuidados, aunque el autor suele mostrarse inclinado, y con fruto, a acunar breves proposiciones, definiciones en la mayoría de los casos, que son pintorescas y agradables. La repetición del sujeto en muchas oraciones, los neologismos no siempre escogidos, los chilenismos, los diminutivos prodigados sin ton ni son forman un conjunto de perturbaciones estilísticas al cual se añaden algunos vulgarismos estrepitosos [...] con lo cual en total se forma un cuadro inelegante, poco armónico, rudo y de mal gusto [desde Hijuna] el autor parece haber descendido en cuanto al estilo y técnica literaria" (1935). Carlos Sepúlveda respondió, en El Diario Ilustrado, a esta crítica, argumentando que Silva Castro confunde autor y protagonista, y que, precisamente, se trata de no "falsear" la vida de Juan de Dios, embelleciéndola. Incluso si se trata de un texto autobiográfico, lo que para él es totalmente irrelevante "¿Va el autor a discursear para abajo, desde los largos años que tiene, para hacer de un muchacho de catorce años, de bravos 14 años, un pobre diablo de cuarenta?" Y, como colofón, apunta a la ideología prevalente en la crítica: "El autor no interesa para nada. La preferencia que usted demuestra por la educación de espíritu liberal, sintetizada por el profesor de Trabajos Manuales, el único simpático que usted encuentra, es ya cuestión que cae en el terreno beligerante de la sociología y que no me corresponde discutir" (1935). 
[...] una cosmovisión crítica y personalísima de nuestra sociedad, de nuestras instituciones políticas, de nuestra burocracia" (52).

\section{4.- EL FINAL: CAMARADA}

La publicación de Camarada fue calificada por el periódico La Nación de Santiago como "la primera obra que se publica entre nosotros de contenido social y político a la vez" (1938). La novela, dice el artículo, "recoge a los maestros primarios en sus luchas políticas y sociales". Quien firma, CPS, critica la escasa recepción que ha tenido, la cual se ha limitado a "solo uno que otro comentario displicente [que] ha aparecido en algunas crónicas literarias". En una de esas pocas reseñas, un crítico del diario La Unión señala que el escritor "baja hacia las grandes agrupaciones humanas de nuestras ciudades, y de ahí extrae las estampas de sus páginas reconcentradas y reflexivas. Ellas más bien captan el dolor que la alegría, y siempre están más a tono con las vidas nimias de los proletarios irredentos que con los falsos arrestos de una falsa clase media" (1939:3). Hay un intento por dar cuenta de la realidad social presente que se enfatiza: "Sus tipos viven y luchan mas allá de las apostasías. Son perfilados robustamente y caminan por la vida interrogando el presente de las cosas. Pasan por sus días y por el tiempo, tendiendo a hacer más expedita la existencia del conglomerado social en que actúan" (3). Efectivamente, hay una gran preocupación por la descripción de la realidad social que se observa, por ejemplo, en la transcripción de avisos que el protagonista lee en la calle ${ }^{17}$ y en la inserción de supuestos artículos de periódico que, de modo similar a lo que acontecía en Hijuna, refieren puntos de vista antagónicos de la situación que viven los maestros. Así, mientras el diario El País inicia la noticia de la exoneración de los profesores señalando que ha sucedido "a causa de los acuerdos subversivos de la convención clausurada ayer" (169) y El Comercio escribe "Exonerados todos los empleados de instrucción que tomaron parte en el Congreso revolucionario e inmoral" (170), el diario La Llama entrega una versión muy distinta: "Los agentes del imperialismo extranjero que desgobiernan este desgraciado país, consiguen arrojar a la cesantía a los más heroicos trabajadores de la enseñanza. ¡256 hogares sin pan!" (171). Los mismos lemas de los periódicos que se despliegan en su disposición original en la página del diario (un pequeño recuadro en la esquina superior izquierda de la portada) dan cuenta de dichos puntos de vista: "Libertad dentro del orden" es el titular que utiliza El País; "Honradez, Fe, Patriotismo", titula El Comercio; y "El hombre libre sobre la tierra libre" es el título de La Llama. Si bien, en una primera instancia parece claro que el narrador está adoptando una determinada postura (y de hecho, se favorece la causa de los maestros); es notable como a lo largo de toda la novela se plantea una consistente crítica al mismo

\footnotetext{
${ }^{17}$ Algunos de ellos: "Se venden huevos frescos del día"; "Se arrienda un departamento a matrimonio honorable tratar en la esquina" (10); o el de una "casa recién acicalada": "Ama joven; limpia, sana, abundante leche, se necesita" (15). Este recurso es otra de las técnicas "modernas" destacadas por Valdivieso.
} 


\section{Daniel Noemi}

movimiento gremial, llegando, como se verá, a la parodia, la ironía profunda e, incluso, al absurdo. La novela concluye con varios de los profesores encarcelados y con Juan de Dios en un rincón de un calabozo, justo antes del amanecer, esperando ese futuro mejor que permite entrever la aurora y la palabra que, en gesto solidario - de apoyo entre los presos - ha dado título a la novela y la concluye: "Y en el corazón estrujado de Juan de Dios, canta el corazón de la tierra amanecida: ¡Camarada!” (1938:296).

Este sentimiento de esperanza, con el que finaliza la trilogía, es el resultado de un proceso crítico complejo y contradictorio. El énfasis en el absurdo de toda la situación desestabiliza cualquier certeza que se pueda tener. Es decir, la novela lleva al lector a un mundo irreal donde no hay lógica ni razón que valgan, y aquí es donde radica la gran paradoja y la gran contribución de Sepúlveda Leyton: el absurdo, ese mundo sin razón, deviene la realidad, la única realidad posible en el presente. Juan de Dios ha recibido una orden de arresto y se dirige a Valparaíso dispuesto a presentarse a la Intendencia. Una vez ahí, es enviado de una oficina a otra, pues en todas le dicen que no hay ninguna causa contra él (a pesar de lo que le ha sido comunicado con anterioridad). De esa manera se llega a dudar que exista la orden de detención que dice tener. La falta de sentido de los acontecimientos se verá reforzada por la posición que adopta el narrador.

En efecto, en esta novela la perspectiva del narrador ya no es la de una primera persona, del Juan de Dios niño o adolescente, sino de una tercera persona que sigue - como una cámara en travelling - al protagonista en su intento por conseguir un cuarto para él y para su familia y, luego, en las reuniones de los maestros y en su lucha sindical. El texto acelera la sensación de fragmentariedad que se percibía en Hijuna. El punto de vista extradiegético permite un mayor distanciamiento con los acontecimientos y no ha de preocuparse por mantener la verosimilitud de la voz de Juan de Dios. No es, por cierto, un narrador que busca la objetividad en el relato: sus descripciones suelen estar marcadas por adjetivos que revelan su posición y profundizan la condición de pobreza e injusticia social que la novela busca destacar. Abundan las personificaciones de objetos, los diálogos oídos al pasar, la inserción de cancioncillas, el empleo de comillas que remarcan la diferencia de los discursos y, por cierto, los diálogos en las escenas de discusión política que intercalan los pensamientos del protagonista, en un uso técnico de la puntuación que otorga la impresión de estar presenciando una escena del teatro de Ionesco. El capítulo XI es, probablemente, el mejor ejemplo de lo recién indicado, cuando presenta una escena donde los maestros discuten en su convención sobre sus posiciones políticas y respecto a qué acciones se deben emprender. El leit motiv que se repite durante el capítulo es el de uno de los "convencionales", la frase "Pero qué manera de perder el tiempo" proferida por "el joven pálido y perezoso", quien "chupa largamente el cigarrillo y exhala en una frase sobremedida la nota opaca de su aburrido cansancio, y todo eso es un bostezo grande" (132). A esta frase, que el narrador intercala en medio de 
los diálogos entre paréntesis y que es, también, la última del capítulo (155), se agregan una serie de repeticiones o "ecos", como los llama el narrador

- ¡El orden por sobre todas las cosas!

- (...cosas...).

- (¡Pero qué manera de perder el tiempo!...).

- (¡No lo decía yo!).

- ¡Rechazar el voto!

- (...voto...) (134).

La situación de caos y de incomunicación crece cada vez más hasta llegar a la total pérdida del orden. El narrador, además, aumenta el sentido de la ironía y la parodia de toda la situación con sus breves descripciones puestas entre paréntesis: "(El Presidente efectivo de la Convención se levanta azorado y empuja a Juan de Dios con el barril que Dios le puso en el vientre)" (135); o "(El Presidente revuelve unos papeles; pero no atina a encontrar el Reglamento. A juego perdido, echa a trabajar el ombligo, y el ombligo es la hélice poderosa que hace arrastrarse el zeppelín del abdomen)" (136). La situación de absurdo es total y, por ello, los mismos discursos políticos que profieren los distintos personajes y las resoluciones que se adoptan, caen en la parodia de sí mismas. El resultado de la Convención se describe del siguiente modo

El arreglo del mundo se hizo a punta de votos; desde el muy discutido, y que por fin se negó el saludo a S. E. el Presidente de la República, hasta el aprobado por unanimidad: el que "exige" la inmediata libertad de los presos políticos del universo entero. Otro voto de enorme trascendencia y que fue aprobado por aclamación al cabo de ser discutido toda la noche, es el que "denuncia" el alza exorbitante del azúcar. Naturalmente ha quedado establecido que todo, tanto la represión política como la especulación traficante, tiene su origen en el amamantamiento del desorden burgués. Y, aunque están todos de acuerdo en ello, nadie se entiende todavía, pues algunos señores convencionales, es decir, algunos discursos, no han podido retractarse ante la Asamblea (157-8).

El evidente tono paródico del narrador construye la crítica del mismo movimiento social. Pero no es un ataque a las ideas que en teoría el movimiento dice defender; es un ataque a la ausencia de verdadero sentido, al vaciamiento del contenido de las ideas al que ha llevado la reiteración de las mismas ideas, que devienen, así, meros ecos de lo que fueron alguna vez. De esta manera, la novela adquiere una notable autoconciencia: la literatura debe estar siempre alerta a no perder su sentido, su poder transformador. Esta pérdida, parece sugerirse, ocurre cuando ciertas fórmulas comienzan a reiterarse una y otra vez (esto puede pensarse en diversos planos); de ahí la importancia del cambio y la innovación (formal y de contenido) para que la literatura (como el movimiento social de la novela) siga produciendo sentido y no cayendo en el absurdo de su existencia. La multiplicidad de recursos y técnicas que emplea Sepúlveda 


\section{Daniel Noemi}

Leyton en sus tres novelas da muestra de cuán consciente el autor se hallaba de este punto.

Por lo demás, el texto desarrolla varios casos específicos de la violencia y la represión ejercidas desde el gobierno. ${ }^{18}$ Uno de los más notables, donde se reúnen el factor de clase social y el de género, corresponde a la argumentación para la exoneración de los profesores. Una profesora relata la historia de Margarita, una madre soltera, que ha tenido que vivir en la miseria. La maestra pide a la convención "un voto de amparo social, de respeto social a la madre soltera, es el que yo traigo" (168). Esa propuesta, muy progresista para la época, junto con el costo que tendría una reforma educacional, es la que se emplea para argumentar que lo que se ha defendido es "el amor libre". ${ }^{19}$ La novela, por medio de una variedad de recursos, presenta las contradicciones y problemas que toda visión y práctica política contiene. La combinación de descripciones e imágenes poéticas (un ejemplo de muchos: "La lluvia habla sola. Mandiola está disfrazado de invierno. Y el invierno está aplastado por un grueso impermeable reversible" (191-2), con los espectaculares quiebres narrativos y la radical ironía que recorre el texto (en lo que constituye un recorrido otro por esa ciudad que es el texto) da cuenta de una doble realidad. Se observa la situación socio-histórica que se vive, la banalidad de muchos de los discursos, la represión del Estado, el sin sentido de la lucha, los problemas que la lucha sindical y política implican; y, también, se está mostrando la realidad de la literatura del momento: del texto que busca describir y caracterizar el caos de la realidad externa, un texto que se inserta en la más contradictoria de las modernidades, de choques y encuentros de temporalidades, donde diversas estéticas confluyen sin asimilarse. Esas dos realidades, encuentros, propios de esta modernidad alocada e incipiente, muestran, asimismo, el conflicto persistente entre arte y política. En efecto, la misma novela hace explícito este encuentro: en un momento Juan de Dios se encuentra con un "buen camarada", un "artista proletario" que recita "con una fuerza de mil caballos" y en una clara alusión irónica a cierta literatura, el narrador comenta: "Versos de acero. Estamos en tiempos de la mecánica. Se acabaron los versos dulzones, las mermeladas con jugo de la vieja alcahueta, la luna. Aeroplanos, tanques, submarinos, usinas, la dinámica del mundo, la esclavitud y la liberación del mundo, resuenan en los versos de ahora; pero - y mucho- desliza sus patines la onomatopeya" (238). A continuación, cita un fragmento del "teatro obrero" del que "(las mujeres no entienden nada, los hombres no entienden nada, Juan de Dios no

\footnotetext{
${ }^{18}$ No resulta difícil observar una crítica social y política contingente en esta novela. El periodo que va de 1924 a 1938 constituye uno de frecuentes cambios políticos y de profunda transformación social (solamente en 1932 hay siete gobiernos). Además, la depresión mundial de 1929, sumada a la brusca caída de los precios del salitre que se venía produciendo desde antes, impactan fuertemente la economía en Chile. Pero, como intento mostrar, la operación crítica de Sepúlveda Leyton es mucho más radical y profunda y no se limita a ser una crítica de su presente.

${ }^{19}$ Uno de los recortes de diario que se incluye señala que los maestros exonerados han llevado a cabo "reiterados propósitos de socavar el orden público para obtener la aprobación de una reforma educacional que costaría al estado más de ochenta millones de pesos, en circunstancias que esta suma ya está destinada a renovar en parte el material de las Fuerzas Armadas” (169).
} 
entiende nada)" (239). La posición del narrador se hace evidente: el arte debe poder ser comunicado, es fundamental poder comprender el mensaje que este tiene (pues, es innegable la función pedagógica que posee el arte y la literatura). Sin embargo, esta comprensibilidad debe darse junto con la apropiación de las nuevas técnicas y estrategias literarias. Estas aparecen no como un mero capricho del escritor sino como necesarias en las circunstancias existentes. He ahí donde radica el gran problema de la literatura para Sepúlveda Leyton y el desafío que enfrentó en toda su producción ¿Cómo hacer compatible la innovación formal con el contenido? En otras palabras ¿Cuál es la articulación política del texto, cuál y cómo es $s u$ política? En el cruce y superación de estéticas realistas y vanguardistas parece hallarse la respuesta que busca, incesantemente, este autor.

Esto puede apreciarse mejor aún cuando el narrador se burla de las novelas sociales y de sus rígidos esquemas. Durante su kafkiano periplo por la Intendencia, buscando la oficina donde le deben decir adónde ir, Juan de Dios "acaricia el placer maligno de burlarse de toda esta máquina de represión" (267). Pero, "ni siquiera puede vanagloriarse de haber sido tratado con grosería" (267), pues todos aquellos funcionarios con quien trata eran "absolutamente correctos, fríos; superficiales unos, graves otros; pero todos caballerosos, de uniforme por fuera y por dentro." (267). Entonces el narrador, focalizado en el protagonista, comenta defraudado: "Esperaba que las escenas se desarrollaran de acuerdo con el estilo clásico de la novelería de la lucha social, y está defraudado. Ojos severos, palabrotas humillantes, patadas en el piso, timbres, carreras, sables, bofetadas en el escritorio [...] Todo eso esperaba Juan de Dios. Y él tenía listo, seguro, arrebatado el grito: “`Viva la U.R.S.S.!” Nada. No había sucedido nada" (267). El anticlímax que defrauda al protagonista se convierte en uno de los momentos centrales de la novela: en él confluye el absurdo, la crítica social, el notable empleo de la perspectiva del narrador y, por cierto, una reflexión fundamental sobre el sentido de la literatura y su relación con la realidad. Explícita es la distinción que la novela busca con respecto a la "novelería de la lucha social"; por cuanto, así se está proponiendo una auténtica novela (no "novelería" superficial) ${ }^{20}$ de la lucha social. Se tratará de una novela que dé cuenta de lo que realmente sucede y no del imaginario (ifolletinesco social?) que ha surgido en torno al tema. El texto busca separarse de la noción panfletaria que se tiene de la novela social y que, por cierto, ha recaído sobre las novelas anteriores de Sepúlveda Leyton. ${ }^{21}$ Este gesto, quizás el más "postmoderno" que

\footnotetext{
${ }^{20} \mathrm{Si}$ bien, claramente el término se emplea con el sentido de "inclinación a fábulas o novelas", acepción segunda que aparece en el diccionario de la Real Academia, los otros dos agregan matices relevantes: "Inclinación a novedades" y, sobre todo, "chisme o novedad superficial".

${ }^{21}$ La transformación de la novela social ha sido un tema largamente discutido desde la perspectiva de la historia literaria. Así, en 1889, ya se llamaba a concurso universitario "sobre el valor histórico de la novela social contemporánea". El trabajo ganador, de Alejandro Fuenzalida Grandón, argumenta a favor del cambio necesario del género novelesco, en general, y de la novela social, en particular; un cambio que se debe a la "ley de evolución". Además, recalca la relevancia parcial de la novela como material histórico. En particular, señala que la novela social contemporánea "puede ser
} 


\section{Daniel Noemi}

se halla en la novela implica una nueva propuesta estética y política, pues no se trata de dejar de lado el contenido social en la literatura sino, por el contrario, radicalizarlo.

\section{CONCLUSIONES}

Hacia una nueva literatura social. El carácter marginal que ha caracterizado la obra de Carlos Sepúlveda Leyton se debe, en parte importante, a su apuesta por una literatura social radicalizada; una que busca socavar las formas convencionales de la novela social pero que, al mismo tiempo, no acepta el mero juego formalista de una vanguardia sin sentido. Es, paradójicamente, una literatura que deviene extemporánea, parece fuera de lugar, mas posee la fuerza para actualizarse y hacerse presente en el momento menos esperado. Es una literatura de profunda crisis, de torbellino y huracán, donde las distintas fuerzas estéticas (románticas, realistas, vanguardistas, modernistas) se hallan en disputa, siempre bajo la égida de una función social y política. Esto último en el sentido más profundo y verdadero posible: toda literatura posee una función social y articula una política; el asunto está en cómo hacer de ella parte de una lucha por la transformación de las condiciones históricas. Esto, que se propone en las novelas revisadas, no implica volver a un realismo socialista que resulta a fin de cuentas totalmente desconectado de esa realidad que pretende tan científicamente describir; tampoco es la exclusiva inmersión en el mundo subjetivo, consciente e inconsciente, donde se halla la respuesta. Esta literatura, la literatura social por la que apuesta Sepúlveda Leyton, es una trayectoria, un recorrido por esa zona difusa que no se deja apresar: es un intento constante de transformación y de permanencia. Literatura urgente que no quiere ni puede desligarse de la vida misma, expresión de sentimiento de una época en crisis; y expresión que hoy, cuando las crisis son otras y las mismas, deviene referente inevitable para pensar la práctica y la crítica de la literatura actual.

Universidad de Michigan, Ann Arbor*

Dept., of Romance Languages and Literatures

D. P: 812 E. Washington St. MLB

Ann Arbor, MI 48105 (USA)

danielnv@umich.edu

\section{BIBLIOGRAFÍA}

Beverley, John. "El Tungsteno de Vallejo: Hacia una reivindicación de la "novela social", en Revista de Crítica Literaria Latinoamericana $\mathrm{N}^{\circ}$ 29. (1989):167-177.

Fuentes, Walter. La novela social en Chile (1900-1925): Ideología y disyuntiva histórica. Minneapolis: Institute for the Study of Ideologies and Literature, 1990.

invocada por el historiador futuro como fuente de información relativa, más o menos cierta, acerca de las ideas y de las costumbres de nuestra época" (40). Empero, como fuente de conocimiento no es "completamente fidedigna", pues la historia "por su espíritu positivo y experimental rechaza lo subjetivo" (40). Más allá del evidente cambio teórico (uno que Fuenzalida admite como posible al final de su ensayo al reflexionar sobre el quehacer del historiador futuro), interesa notar la compleja relación que se establece entre novela, historia y esa escurridiza realidad externa. 
Fuenzalida Grandón, Alejandro. Valor histórico de la novela social contemporánea. Santiago de Chile: Imprenta Nacional, 1889.

Gil Casado, Pablo. "La novela social en España”, en Cuadernos Americanos $\mathrm{N}^{\circ}$ 154-5 (1967):230-236.

Guzmán, Nicomedes. “Carlos Sepúlveda Leyton, novelista del pueblo”, en Atenea $\mathrm{N}^{\circ}$ 189 (1941):354-361.

------- "La Fábrica”, en Revista Hoy. Santiago, 27 de septiembre, 1935:39.

------ "La Fábrica”, en La Nación. Buenos Aires, diciembre 22 de 1935: Sección 2:4.

------ “Impresiones: Camarada". La Unión. Valparaíso, 10 de marzo, 1939:3.

Osorio, Nelson. "Sepúlveda Leyton: tradición y modernidad", en Anales de la Universidad de Chile $\mathrm{N}^{\circ}$ 141-144 (1967):55-73.

Ridenti, Marcelo. Em Busca Do Povo Brasileiro: Artistas Da Revolução, Do Cpc a Era Da Tv. Río de Janeiro-Sao Paulo: Record, 2000.

Rivas, Ramiro. "El regreso de una época”, en Diario La Época, Suplemento Literatura \& Libros. Santiago, 22 de octubre, 1995:3.

Sepúlveda Leyton, Carlos. Hijuna. Santiago de chile: LOM, 1995.

------ Camarada. Santiago de Chile: Nascimento, 1938.

------ La Fábrica. Santiago de Chile: Ercilla, 1935.

------ "La Fábrica, de Carlos Sepúlveda, explicada a uno de sus críticos”, en El Diario Ilustrado. Santiago, 22 de septiembre de 1935.

Silva Castro, Raúl. “La Fábrica, por Carlos Sepúlveda Leyton”, en Diario El Mercurio. Santiago, 16 septiembre de 1935.

Valdivieso, Jaime. Un asalto a la tradición. Santiago de Chile: Alerce, 1963.

Vitale, Luis. Sociología de la novela y vida cotidiana en el Chile de 1900 a 1950. Santiago de Chile: Puerto de Palabras, 2001. 